\title{
Reconfigurações do olhar: o háptico na cultura visual contemporânea
}

\section{Resumo}

Nos últimos anos, temos observado em diversas práticas visuais uma tendência em se trabalhar com imagens imprecisas e instáveis, imagens precárias que abrem mão da clareza e da distância, demandando um novo tipo de olhar - um olhar mais atento à superfície, aos detalhes, aos pequenos eventos que emergem na imagem. Este é um tipo de visualidade que podemos definir, juntamente com Gilles Deleuze e Felix Guattari, como háptica, um tipo de imagem que induz um espaço e um tipo de percepção mais tátil do que visual, uma percepção próxima, funcionando pelo tato. $\mathrm{O}$ intuito desse texto é pensar o que está em jogo nesse tipo de proposta visual. Trata-se aqui de investigar que novos agenciamentos estéticos e epistemológicos são produzidos por essas imagens.

\section{Palavras-chave:}

Reconfiguração do olhar, visualidade háptica, contemporâneo 


\title{
Reconfigurations of the gaze: the haptic in contemporary visual culture
}

\author{
OSMAR GONÇALVES DOS REIS FILHO
}

\begin{abstract}
In recent years, we have observed in several visual practices a tendency to work with inaccurate and unstable images, images who give up clarity and distance, requiring a new way of looking - a closer look at the surface, at the details, the small events that emerge in the image. This is a kind of visibility that we can define, with Gilles Deleuze and Felix Guattari, as haptic, a type of image that induces a space and a kind of perception more tactile than visual, a close perception, working by touch. The purpose of this paper is to think what is at stake in this kind of visual proposal. It is to investigate what new aesthetic and epistemological assemblages are produced by these images.
\end{abstract}

Keywords: Viewing Reconfigurations, haptic visuality, contemporary 


\section{Introdução}

Nos últimos anos, temos observado em práticas visuais diversas uma tendência em se trabalhar com imagens imprecisas e instáveis, imagens precárias, que mais esboçam e sugerem seus objetos do que propriamente os representam. Trata-se de uma tendência pervasiva, algo que pode ser observado tanto no campo da fotografia - no trabalho de fotógrafos como Gui Mohallen, Breno Rotatori e Haroldo Sabóia, a chamada geração oo - quanto no universo do cinema, marcadamente no cinema asiático de Naomi Kawase, Apichatpong e Wong Kar-Wai; quanto nas produções ligadas à videocriação, nas obras de artistas como Gary Hill, Pipilotti Rist, Eder Santos e Rodrigo Minelli.

De fato, todos esses realizadores parecem apostar numa espécie de crise ou de falência da visão. Em suas obras, há sempre algo que não se vê, há sempre alguma coisa que permanece fora da imagem, que se mantém invisível, misteriosa, ainda por vir. Eles trabalham com imagens obscuras, distorcidas e procuram estabelecer, quase sempre, uma enorme proximidade com os objetos filmados. Aqui, a câmera cola na pele e nos corpos dos personagens, se mistura à matéria filmada, explorando o grão e a textura, enquadrando os objetos de muito perto, de tão perto que os torna praticamente irreconhecíveis.

Nesse contexto, notamos uma mutação no estatuto da visão. Diante dessas obras, o olhar vê obrigado a abandonar a clareza e a distância típicas da produção visual corrente, a ceder certo grau de domínio ou de controle sob o que está vendo e colocar em movimento um outro modo de ver - uma outra economia do olhar. Trata-se de um olhar mais íntimo e cuidadoso, um olhar próximo, atento aos pequenos detalhes, aos pequenos eventos que emergem na superfície da imagem. 
Ora, esse é um tipo de proposta visual bem distinta daquela encontrada na produção visual hegemônica. O que temos aqui é um tipo de visualidade que poderíamos qualificar, juntamente com Gilles Deleuze e Félix Guattari, como háptica. Isto é, um tipo de imagem que induz um espaço e um modo de percepção mais tátil do que visual, uma imagem que demanda uma percepção próxima, funcionando pelo toque. Na visualidade háptica, afirmam os filósofos franceses, os olhos funcionam, eles mesmos, como órgãos de toque, como uma forma de contato. Mais do que ser projetado numa estrutura centralizada ou num espaço ilusionístico profundo, o olhar tende aqui a se aproximar do corpo da imagem, a correr por sua superfície, hesitando e demorando-se sobre inúmeros efeitos de superfície.

Nesse artigo, gostaríamos de investigar o que está em jogo nesse tipo de visualidade. $\mathrm{O}$ que leva um número cada vez maior de artistas a lançar mão dessas imagens? Que novos agenciamentos são produzidos nesses trabalhos? Nossa hipótese é de que essas mudanças não têm um caráter formal apenas, mas trazem implicações estéticas, éticas e epistemológicas. Isto é, elas refletem a emergência de outro modo de percepção, de novas sensibilidades. Mais do que um estilo ou um modo de formar, é uma nova maneira de se relacionar com as imagens e com o mundo, outro modo de estar-no-mundo que está em questão aqui.

De um lado, parece-nos que a visualidade háptica está ligada àquilo que Hans Ulrich Gumbrecht chamou desejo de presença, isto é, a vontade do homem contemporâneo de restabelecer um contato mais sensível e corporalizado com os objetos e com as imagens em si mesmas (GUMBRECHT, 2004). Nessa perspectiva, a visualidade háptica seria responsável por restituir - numa cultura predominantemente hermenêutica e cartesiana como a nossa - formas de comunicação mais corpóreas e imediatas (não-mediadas), experiências nas quais podemos experimentar não apenas o domínio da representação e do simbólico, mas a própria presença das coisas, a materialidade dos objetos e dos meios, o poder criativo da representação não-figurativa - das linhas e das forças (o invisível, o impalpável, o que está em devir) e não somente das formas (estáveis).

De outro, a busca por imagens hápticas parece refletir certa insatisfação com os limites da visualidade dominante. Isto porque essa visão que se tornou dominante a partir do Renascimento, a visão distante e centralizada, mostra-se hoje 
incapaz de expressar certas memórias (e sensações) mais associadas a outros sentidos, como o tato e o olfato. No geral, esses sentidos funcionam através da proximidade e do contato físico. Sob outro ponto de vista, esse desejo pela visualidade háptica parece estar associado ainda à necessidade de se reconsiderar a visão no contexto cultural contemporâneo, à premência de se rever e problematizar essa visualidade dominante tão associada hoje, como já demonstraram T. W. Mitchel e David Michael Levin, às noções de controle, domínio e instrumentalidade.

\section{Outros olhares, novas formas de percepção}

Mas, antes de tudo, o que vem a ser o háptico? Em que medida ele se diferencia do ótico? Qual a relação que estabelecem entre si? Segundo a teórica americana Laura Marks, ainda que o termo háptico não seja exatamente novo, ele ganha novo destaque no pensamento contemporâneo a partir das descrições de Deleuze e Guattari sobre o espaço liso. Um tipo de espaço marcadamente próximo e contingente, que precisa ser movido através da constante referência ao ambiente imediato, como quando atravessamos uma extensão de neve ou de areia. Para Deleuze e Guattari, espaços próximos e fechados são navegados não através da referência às abstrações de mapas ou compassos, mas por meio da percepção háptica, que atende a sua particularidade. Em O liso e o estriado, os pensadores franceses afirmam que o liso "é simultaneamente o objeto de uma visão fechada por excelência e o elemento de um espaço háptico. O estriado, ao contrário, remete mais a uma visão distante, e mais a um espaço ótico - embora o olho não seja o único órgão a ter essa capacidade" (DELEUZE e GUATTARI, 1997, p.19o).

Neste belo ensaio, Deleuze e Guattari não só recuperam o conceito como jogam nova luz sobre ele, contribuindo para reacender as pesquisas ao redor da imagem e da percepção hápticas. Eles remetem sua origem ao historiador da arte Aloïs Riegl que, na virada do século XX, teria cunhado o termo para designar certas tradições na história da arte que se caracterizam, justamente, por trabalhar com um espaço liso, próximo, espaços que não oferecem um ponto de vista exterior imóvel e centralizado.

Riegl define a visualidade háptica como aquela que solicita o espectador não apenas através dos olhos, mas, pela sua enorme proximidade, também ao longo da pele. Ele contrapõe a visualidade háptica a uma visualidade óptica. Mostra que 
enquanto esta última vê as coisas de uma grande distância, tornando possível distinguir claramente suas figuras num espaço profundo; enquanto ela depende de uma clara separação entre o sujeito observador e seus objetos, requerendo distância e um centro, o olhar háptico não possui centralidade. Ele tende a se mover sobre a superfície de seus objetos, ao invés de mergulhar na profundidade ilusionística. Está mais inclinado a se mover do que a focar, opera não tanto para distinguir as formas quanto para discernir texturas.

Curiosamente, Riegl foi um curador de têxteis, antes de se tornar acadêmico. É interessante imaginar, como já sugeriu Marks, o quanto essa atividade, que o fazia passar horas a fio a poucos centímetros de um tecido ou de um carpete, deve ter estimulado suas idéias sobre uma modalidade de olhar próxima e tátil. Suas descrições evocam a ação do olhar em superfícies planas e texturas raramente figurativas.

Em Riegl, a história da arte tem uma característica marcante e fundamental. Ela aparece associada ao gradual desaparecimento de uma tatilidade física na arte e a ascensão e crescimento de um espaço figurativo. Riegl observa esse desenvolvimento na transição da arte egípcia antiga, cujo estilo é tipicamente háptico, para a arte romana tardia, que já aparece marcada por um estilo ótico. Como esclarece o historiador vienense, a primeira sempre teve como elemento a superfície plana. Nela, os planos não se encontram separados, não há uma perspectiva que os atravesse, uma ilusão de profundidade na qual seríamos convidados a nos projetar. Na arte egípcia, o espaço é fechado, próximo, as figuras aderem ao plano. Há, portanto, uma valorização da superfície, da concretude, da materialidade da imagem. Enxergá-las é como proceder a uma forma de contato. Mais do que ver, nos diz Deleuze quando analisa a baixo-relevo egípcio, temos a sensação de tocar esses objetos (DELEUZE, 2007).

Já na arte romana, os objetos começam a se destacar do plano. Segundo Riegl, é neste momento que a visualidade ótica emerge, quando, no final do império romano, começamos a observar nas pinturas e nos trabalhos em metal, uma clara distinção entre figura e fundo, e a conseqüente construção de um espaço abstrato, de uma ilusão de profundidade. A partir daí, o espaço deixa de ser pensado como algo concreto, físico, ligado a superfície e passa a ser estriado, nos termos de Deleuze e Guattari. Ele passa a ser concebido/projetado como uma forma ilusionística. Eis que os objetos deixam de ser desenhados na superfície e passam a povoar, cada vez mais, 
esse espaço abstrato profundo. Ora, como esclarece Riegl essas mudanças não são apenas alterações de ordem formal ou estilística, elas trazem conseqüências decisivas para a própria percepção. Senão vejamos.

Em primeiro lugar, é preciso notar que nessa configuração, os objetos perdem algo de sua materialidade, de sua conexão física com o plano. Nas palavras de Riegl, "com o aumento do espaço e da tridimensionalidade, a figura no trabalho de arte também é cada vez mais desmaterializada" (RIEGL, 1985, p.74). Isso quer dizer, entre outras coisas, que os objetos perdem parte de sua tatilidade física, e que as imagens, a partir de então, deixam de privilegiar o contato físico e sensorial com o espectador para valorizar, cada vez mais, a representação e o simbólico.

Em segundo lugar, no momento em que são projetadas em um espaço profundo, as figuras se distanciam do observador. Como nota Antonia Lant, a emergência desse espaço abstrato tornou possível para um espectador identificar figuras não como elementos concretos numa superfície, mas como objetos no espaço (LANT, 1995, p.45-73). Em outros termos, a representação ótica tornou possível uma grande distância entre o espectador e o objeto, uma distância tal que o permite não só identificar, mas se projetar imaginariamente neste objeto. Dessa maneira, o espaço ilusionístico tornou possível, ou pelo menos facilitou, toda a dinâmica da identificação e da projeção que constitui um dos pontos cruciais da recepção cinematográfica. Aqui, mais do que entrar em contato com os objetos, com as imagens, mais do que sentir sua presença, somos convidados a nos projetar em um espaço ilusório.

No que diz respeito à visualidade háptica, ela não depende desse processo de identificação com objetos figurativos. Em seus relatos como curador de têxteis, Riegl deixa claro que a visualidade háptica raramente nos oferece imagens figurativas. Ela sugere, indica, esboça figuras, mas dificilmente as representa completamente. Ao invés de tornar o objeto totalmente disponível à visão, ela parece colocá-lo em questão.

Por fim, Riegl afirma que a partir dessa passagem operada pela arte romana vai haver uma valorização cada vez maior do espaço abstrato. Ele tende a se expandir e a se desenvolver nos séculos seguintes. A invenção da perspectiva renascentista, por exemplo, se inscreve nessa trajetória e representa um passo decisivo na busca de um espaço ilusionístico. De fato, ela aprimora significativamente a ilusão de profundidade, e consolida a idéia de um espaço que não é mais um plano, a ground plane, mas uma formação ideal e ilusória. Além disso, a pers- 
pectiva centraliza a visão do espectador, reforçando a posição de um indivíduo que se vê diante dos objetos, separado deles, podendo, de certa maneira, controlá-los, dominá-los. Trata-se aqui, portanto, de uma visão distanciada, centralizada, que deixa de funcionar como uma forma de contato, como uma experiência marcadamente sensorial, para funcionar como uma operação simbólica.

Em Late Roman Art Industry, Riegl argumenta que o desenvolvimento da arte no Ocidente é realmente marcado por uma abstração crescente, por uma adesão cada vez maior ao simbólico. No ensaio já comentado aqui, Deleuze e Guattari confirmam a visão de Riegl e apontam a invenção da perspectiva como um elemento crucial na formação desse espaço figurativo e simbólico. Para os filósofos franceses, estava claro que o liso era um espaço de liberdade, um espaço anterior à sistematização, à ordenação geométrica, matemática, um espaço onde não há uma separação muito clara, entre figura e fundo, entre sujeito e objeto, dentro e fora. O espaço liso não reforça o ponto de vista de um indivíduo, não o coloca em uma situação de domínio (como o senhor do conhecimento), nem depende de um processo de identificação com figuras projetadas no quadro.

Como diz Marks, o espaço próximo, liso, "não convida a identificação com uma figura, tanto quanto ele encoraja uma relação corporal entre o espectador e a imagem" (MARKS, 2002, p.3). Mais do que nos projetar em um espaço ilusório, ele encoraja um contato sensível e corporalizado com as imagens, um contato no qual podemos experimentar a materialidade dos meios e o poder criativo da representação não-figurativa, das linhas e formas abstratas - daquilo que Merleau-Ponty chamou, em outro contexto, de ramos da imagem (MERLEAU-PONTY, 2004).

No entender de Deleuze e Guattari, "a linha abstrata é o afeto dos espaços lisos, não um sentimento de anxiedade que suscita estriamento. O organismo é um desvio da vida" (DELEUZE e GUATTARI, 1997, p.187). Para os filósofos, a linha abstrata representa a própria vida. Ambas têm como elemento a diversidade, a modulação constante, estão sempre escapando às estruturas, às forças do enrijecimento e da sistematização, sempre em defasagem consigo mesmas. A emergência da perspectiva renascentista, contudo, fará o liso ceder lugar ao estriado e, a partir daí, vamos assistir a hegemonia da figuração, do espaço simbólico e cartesiano.

Apesar disto, a visualidade háptica não deixa de existir. Riegl observa modos de representação háptica em tradições, 
normalmente, consideradas minoritárias em relação à história "oficial" da arte ocidental. Além da pintura egípcia e de alguns trabalhos em metal no período tardio da arte romana, o historiador vienense cita a pintura islâmica, as iluminuras medievais, a arte rococó do século XIX, especialmente na França, a pintura a óleo flamenca, entre os séculos XV e XVII, entre outros.

Todas essas tradições envolvem imagens próximas, detalhadas, imagens que convocam um olhar íntimo e cuidadoso. Normalmente, a história da arte tem considerado tanto essas imagens quanto esse modo de olhar, secundários em relação às grandes composições, aos grandes temas e à posição exaltada do espectador. Não obstante, o número de pesquisas sobre eles tem crescido ao longo das últimas décadas. Atualmente, um número significativo de historiadores da arte tem sugerido que modos alternativos de olhar, que outras economias da visão, sempre conviveram com a representação ótica dominante. É o que nos mostra o pensamento anti-visual francês do século XX presente em autores como Sartre, Foucault e Merleau-Ponty que apresentam uma perspectiva céptica ou negativa da visão, questionando o ocularcentrismo reinante e o privilégio que é historicamente concedido à visualidade óptica no pensamento Ocidental, particularmente a partir da modernidade. Em Touch, Laura Marks cita vários pesquisadores que também desenvolvem trabalhos nessa direção, como Svetlana Alpers, Norman Bryson, Steven Shaviro, Naomi Schor, Mieke Bal, Jennifer Fisher, entre outros.

A americana Svetlana Alpers, por exemplo, estuda a pintura holandesa do século XVII, e descreve a partir dela um modo de ver no qual os olhos pairam - se demoram, hesitam - sobre inúmeros efeitos de superfície, ao invés de serem puxados para grandes estruturas centralizadas, como ocorre em boa parte da pintura ocidental contemporânea. Bryson desenvolve o conceito de glance (vislumbre, olhadela) em contraposição à noção, já bem teorizada, de gaze (olhar fixo, contemplativo). O termo Glance sugere um modo de ver que não se alia com uma posição de controle ou de domínio, nem depende de uma estrutura centralizada para operar. Naomi Schor, por sua vez, defende que o detalhe tem sido codificado como feminino, como negatividade, e, por isso, vem sendo reprimido na tradição ocidental. A partir daí, ela propõe uma complexa estética do detalhe, na qual predomina um tipo de olhar próximo e lábil. 


\section{Imagens íntimas, sussurradas}

O mais surpreendente nessas pesquisas, no entanto, é que elas apontam, muitas vezes, não apenas para uma convivência entre diversos modos de olhar, mas para uma verdadeira renascença da visualidade háptica nas últimas décadas do século passado. Para teóricos como Steve Shaviro e Laura Marks, nós estaríamos vivendo um momento de retorno às formas hápticas de representação. E, de fato, é exatamente isto o que se nota, quando observamos os desenvolvimentos da arte no pós-guerra. Seja no expressionismo abstrato ou na arte pop, seja no minimalismo ou na arte neoconcreta, encontramos uma mesma valorização do olhar íntimo e tátil. No campo das imagens em movimento, o cinema contemporâneo asiático e o vídeo de criação se apresentam como o lócus privilegiado desse retorno. Neles, a opção pelas formas não-narrativas e sensoriais, pela imagem próxima e instável, põe em jogo uma percepção predominantemente háptica.

Dentre os vários exemplos possíveis nesse universo, gostaríamos de estabelecer um breve diálogo com o vídeo Planoconsequência (2005), do realizador mineiro Rodrigo Minelli. Esse trabalho íntimo, visceral, nos permite pensar de modo exemplar algumas das questões e dos problemas abordados até aqui. Dividido em dois movimentos, Plano-consequência (2005) começa com imagens difíceis de ver, imagens precárias, feitas no escuro, com o auxílio de luz infravermelha. São imagens próximas, tão próximas dos personagens (o próprio Minelli e sua esposa) que se torna difícil reconhecê-los. O que vemos são cenas de intimidade, é certo, mas o que se passa ali, quem são ou onde estão aquelas pessoas, não conseguimos distinguir. Sexo, discussão, êxtase? Não se sabe. A câmera colada à pele e aos corpos, só consegue arrancar dos personagens imagens sussurradas. Imagens imprecisas, cheias de afeto e textura, mas longe de qualquer narrativa ou explicação.

Além de serem captadas no escuro, as imagens sofreram distorções eletrônicas (falhas, ruídos, drop-outs) que dificultam ainda mais nossa visão. $\mathrm{O}$ áudio também contribui para essa indeterminação do vídeo, pois não condiz com as imagens vistas. Há aqui uma autonomia, uma dissociação entre imagem e som. O que ouvimos é, na verdade, um diálogo imaginário entre os poetas Sylvia Plath e Vladimir Mayakovski. Nele, sob uma trilha de suspense cuidadosa, criada por Ronaldo Gino e André Melo, Plath ameaça Mayakovski de morte, afirma que ele não compreende (assim como todos os 
homens), que é incapaz de compreender, mas que verá. Algo o espera, ela diz, e o movimento trêmulo e indeciso da câmera parece criar mesmo uma forte sensação de expectativa. Fim do primeiro movimento.

Neste vídeo, Minelli abandona toda distância, toda centralidade e clareza óticas para nos envolver em uma corrente de impressões táteis. A câmera não só passeia sobre a pele do casal, mas acaba se fundindo, se confundindo com eles. Aqui, perdemos a noção de nossos próprios limites, misturamo-nos ao que é filmado, somos fortemente envolvidos na experiência. Plano-consequência cria um novo tipo de imagem, uma que poderíamos chamar de imagem-experiência, produzida na proximidade, no contato ou no encontro entre os corpos: o corpo dos personagens, corpo da câmera e do espectador. Essa imagem ativa uma percepção verdadeiramente háptica, funcionando pelo tato. Ela nos mostra a textura do beijo, as fissuras da carne, o arrepio do pelo, todos esses sentimentos ínfimos que se expressam na superfície. E exige por essa extrema proximidade com o outro e com a própria materialidade do vídeo (o pixel, a trama, os ruídos), um abandono de si, um deixar-se levar pelo que é mostrado. Eis aí o erotismo do vídeo!

De volta à escuridão do quarto, ouvimos trechos de uma transmissão radiofônica e passos num corredor. A imagem então se apaga (fade out) e tem início o segundo movimento do vídeo. Uma maca corre pelo corredor de um hospital e logo vemos uma mulher em posição de parto. Novamente em um quarto semi-escuro, a câmera mostra o nascimento de um bebê: justamente a conseqüência do título. Minelli não tem pudor de filmar aqui a vagina, a placenta e o sangue escorrendo. Sua câmera é próxima, mostra o nascimento em plano detalhe e a força das imagens reside justamente na sua proximidade. Partilhamos dessa experiência única com ele, sentimos seu corpo junto ao que vemos. Há nessas imagens, de fato, uma intensa intimidade, um afeto verdadeiro que passa pela presença física (o corpo de Minelli e de sua mulher) do realizador. Toda experiência do vídeo, aliás, está fundamentalmente ancorada nos corpos ali envolvidos.

\section{O desejo de presença na cultura visual contemporânea}

Nas últimas décadas, muitos artistas têm demonstrado um interesse renovado pela visualidade háptica. Nossa hipótese é de que esse retorno teria, pelo menos, duas razões principais. Por um lado, ele estaria ligado a um desejo de presença, à ne- 
cessidade premente do homem contemporâneo por imagens e formas de conhecimento mais corpóreas e sensoriais, por experiências mais imediatas (não-mediadas). Por outro, ele expressaria uma insatisfação da cultura hodierna com os limites da visualidade dominante. Pois essa visão distanciada e central se mostra mesmo incapaz de expressar certas memórias (e sensações) que estão enraizadas ou que nos vêm de outros sentidos, como o tato e o olfato. Por vezes, essa insatisfação também se revela como uma suspeita ou como uma crítica à visão.

No campo da fotografia, obras como Ensaio para a Loucura (2008), de Gui Mohallen e Bloco de Notas (2009), de Breno Rotatori trabalham explicitamente essa crítica. Já no campo do audiovisual, vídeos como Shoot for the Contents (1991), de Trinh, Flow (1993), de Yau Ching, Ocularis: Eye Surrogates (1997) e Ekleipsis (1999), de Tran T. Kim-Trang [The Blindness Series], exploram esse questionamento de modo claro e até mesmo ostensivo.

Obviamente, essa crítica não se endereça a todo e qualquer tipo de visão, mas aquele modelo que se tornou hegemônico a partir do Renascimento. Vários teóricos têm qualificado essa visualidade como instrumental, como uma visão que busca apenas apreender e controlar seu objeto. De fato, ela parece operar a partir da clássica oposição sujeito objeto. É uma visão distanciada, que se coloca diante do mundo. Não com ele ou junto dele - a exemplo do que propõe Merleau-Ponty com o conceito de visível - mas separada do mundo, a ele transcendente, podendo tomá-lo, portanto, como objeto (MERLEAU-PONTY, 2005). Trata-se, sem dúvida, de uma visão cartesiana, que além de separar o eu do mundo e dos outros, tende a objetificar o outro, a usá-lo para fins de conhecimento e controle.

Como nos mostra David Michael Levin, visão e visualidade se tornaram um dos grandes temas da pesquisa contemporânea (LEVIN, 1993). E vários teóricos, entre eles T. W. Mitchell, Trinh T. Minh-ha, Fatimah Rony, têm reconsiderado a visão, classificando-a como instrumental ou não-instrumental, objetificante ou intersubjetiva, visão alinhada com controle, domínio e visão que permite ao seu objeto permanecer misterioso.

No caso da visualidade háptica, nós somos confrontados com imagens precárias, imagens que nos aparecem como um vestígio, como um esboço, algo ainda por vir. São no geral imagens difíceis de ver, que parecem manifestar uma espécie de crise ou falência da visão. Diante delas, de fato, o olhar é precário e a visão se vê obrigada a abandonar um certo grau de domínio e de controle. 
Nesse universo, as imagens apontam quase sempre para um limite. Há sempre algo que não se vê ou que não se vê completamente. Há sempre alguma coisa que permanece fora da imagem, que se mantém invisível, misteriosa, ainda por vir. Aqui, os objetos da visão são mais sugeridos e esboçados do que propriamente representados. Muitas das vezes, eles são postos em questão, nos aparecendo estranhos, transformados, desfigurados. Seja num caso ou em outro, o espectador é encorajado a se envolver de modo mais crítico com a imagem. Ele é convidado a abandonar uma postura passiva e a participar na construção imaginativa da imagem, a preencher suas lacunas. Vivian Sobchack chama esse tipo de visão de volitiva ou deliberada (SOBCHACK, 1992). Para a teórica americana, ele se distingue de um modo acrítico, aparentemente pré-determinado de visão, na medida em que o espectador deve trabalhar ativamente para constituir a imagem, para trazê-la do estado de latência em que se encontra, de sua infância, diríamos.

De acordo com Laura Marks, esse modelo volitivo ou háptico de visão escaparia à qualificação de instrumental ou objetificante. Ao invés de estar associado ao controle (típicos da visualidade ótica), ele teria uma qualidade mais propriamente erótica. Segundo Marks, esse erotismo vem da relação próxima, tátil e encarnada que a visualidade háptica encoraja. Nela, somos convidados a abrir mão da distância, da clareza ótica e nos aproximar do corpo da imagem, colocando em movimento um olhar íntimo e detalhado. Aqui, trata-se, antes de tudo, de acariciar, de tocar o outro, não de apreendê-lo ou dominá-lo. Mesmo porque na imagem háptica este outro só nos aparece incompleto, envolto em uma aura de mistério.

É preciso ressaltar também que ao estabelecermos uma relação de proximidade, o sujeito muitas vezes perde a noção dos seus limites. Há uma espécie de confusão ou de entrelaçamento entre sujeito e objeto, uma indivisão entre o senciente e o sentido, tal como descrevia Merleau-Ponty. Nessa relação, de fato, há um abandono do sujeito no contacto com o outro. Em outras palavras, ele abre mão de um controle sobre si e de um controle sobre o outro. E isto seria a quintessência mesma do erótico: a capacidade de oscilar, de se mover entre o doar-se e o receber, entre o abandono e o controle de si.

Nas palavras de Marks (2002, p.20):

O que é erótico na visualidade háptica, então, pode ser descrito como o respeito pela alteridade, e a concomitante perda de si na presença do outro. Erotismo é o encontro com um 
outro que se delicia diante de sua alteridade, mais do que tenta conhecê-la. O erotismo visual possibilita à coisa vista manter sua incognoscibilidade, se deliciando em jogar na fronteira do cognoscível. O erotismo visual permite ao objeto da visão permanecer insondável.

\section{Referências}

DELEUZE, G. e GUATTARI, F. O liso e o estriado. Trad. Peter Pál Pelbart. In. Mil Platôs - capitalismo e esquizofrenia. São Paulo: Ed. 34, 1997.

DELEUZE, Gilles. Cada pintor resume à sua maneira a história da pintura. In: Francis Bacon: lógica da sensação. Rio de Janeiro: Jorge Zahar, 2007.

LANT, Antonia. Haptical Cinema. October 75, 1995.

LEVIN, David Michael. Modernity and the Hegemony of Vision. Berkeley: University of California Press, 1993.

MARKS, Laura k. Touch: sensous theory and multisensory media. Minneapolis/London: University of Minnesota Press, 2002.

MERLEAU-PONTY, Maurice. O olho e o espírito. Trad. Paulo Neves e Maria Gomes Pereira. São Paulo: CosacNaify, 2004. . O visível e o invisível. Trad. José Artur

Gianotti. São Paulo: Perspectiva, 2005.

RIEGL, Alöis. Late Roman Art Industry. Trad. Rolf Winkes.

Rome: Giorgio Bretschneider Ed., 1985, p74.

SOBCHACK, Vivian. The Address of the Eye: Phenomenology and Film Experience. Princeton: Princeton University Press, 1992.

Recebido em: 11/12/11

Aceito em: 03/12/12 
OSMAR GONÇALVES DOS REIS FILHO osmargoncalves@hotmail.com

É doutor em Comunicação pela Universidade Federal de Minas Gerais (UFMG), com bolsa-sanduíche na Bauhaus Universität-Weimar (Alemanha), financiada pelo DAAD/CAPES. Pesquisador e fotógrafo, possui graduação (2001) e mestrado (2003) pela Faculdade de Filosofia e Ciências Humanas da UFMG. Atualmente é professor da Pós-graduação em Comunicação e do curso de Cinema e Audiovisual da Universidade Federal do Ceará, concentrado principalmente nas áreas da teoria da imagem, fotografia e estética do audiovisual. 